\title{
Analysis of the Effect of Supplying Vessel on Wave Drift Force of Semi-Submersible Platform
}

\author{
Chi Zhang*, Baoji Zhang \\ College of Ocean Science and Engineering, Shanghai Maritime University, Shanghai, China \\ Email: ${ }^{562991008 @ q q . c o m ~}$
}

How to cite this paper: Zhang, C. and Zhang, B.J. (2019) Analysis of the Effect of Supplying Vessel on Wave Drift Force of Semi-Submersible Platform. Open Journal of Modelling and Simulation, 7, 169-176. https://doi.org/10.4236/ojmsi.2019.73009

Received: June 1, 2019

Accepted: July 1, 2019

Published: July 4, 2019

Copyright () 2019 by author(s) and Scientific Research Publishing Inc. This work is licensed under the Creative Commons Attribution International License (CC BY 4.0).

http://creativecommons.org/licenses/by/4.0/

\section{(c) (i) Open Access}

\begin{abstract}
Wave drift force is the key factor affecting the mooring ability of semi-submersible platform. Aiming at the mooring system composed of replenishment ship and semi-submersible platform, the influence of hydrodynamic interference on semi-submersible platform is analyzed. Based on the three-dimensional potential flow theory and AQWA software, the effects of different wave directions and spacing on the wave drift force of semi-submersible platform are considered. The results show that the hydrodynamic interference of the replenishment ship will affect the wave drift force of the semi-submersible platform, and the influence of the distance between adjacent vessels and the wave direction angle is more sensitive in the middle and high wave frequencies. This paper can provide support for the research of hydrodynamic interference of semi-submersible platform.
\end{abstract}

\section{Keywords}

Semi-Submersible, AQWA, Wave Drift Force, Potential Theory

\section{Introduction}

Semi-submersible platforms are widely used in petroleum development because of their good resistance to wave motion. Generally, semi-submersible platforms are affected by environmental loads such as wind, waves, and currents. Therefore, mooring systems are used to ensure the normal and safe operation of the platform. The motion response of semi-submersible offshore platforms is generally divided into wave-frequency motion and low-frequency motion. Due to nonlinear loads, low-frequency wind loads and flow loads tend to cause long-period, large-scale resonance of the platform, which will generate a large stress response to the mooring system [1]. When the supply ship and the semi-submersible platform are in the same flow field, the average drift force of 
the semi-submersible platform is more complicated.

For the hydrodynamic disturbance between different floating structures in the same flow field, Ohkusu [2] used the two-dimensional slicing method to study the swaying problem of the hull around another structure. The research results show that the small floating body is in the big floating body and the wave. The hydrodynamic response in the case of back waves is different, and there is a relatively obvious wave shielding effect. Studying multi-floating hydrodynamic disturbances, analysis of second-order wave forces is essential. When the two floating structures are close to each other, the coupling between them affects the hydrodynamic performance of each other. The most common methods for calculating wave drift force are the near-field method and the far-field method. The near-field method is proposed by Ogilvie [3]. By integrating the pressure on the wet surface, the average drift force of the waves in the six degrees of freedom of the floating body can be calculated by this method. Islam [4] used the far-field method to analyze the wave drift force of the berthed FPSO and LNG, and then compared with the test results, which is more reliable. Hong, Kim et al. [5] simulated the regular wave and the hydrodynamic disturbance of multi-ship berthing under the action of irregular waves. Through numerical simulation and experimental analysis, the drift force and motion response of the three ships were studied. Joao and Fonseca [6] used the three-dimensional potential flow theory to study the average drift of the two ships.

For the semi-submersible offshore platform, Wang Ke et al. [7] [8] considered that the average wave drift force is the main factor in the design of the mooring system. When calculating the average wave drift force, it is necessary to consider the influence of the semi-submersible platform diffraction and radiation motion. Hydrodynamic disturbance will cause the semi-submersible platform to respond to changes in environmental parameters. Zhou et al. [9] used LNGC to rely on FLNG, using the combination of experiment and numerical simulation to reveal the influence of different wave directions on the average wave drift force. Under the influence of external environment, the hydrodynamics of the multi-floating structure is more complicated than that of the single floating body. The spacing between the two has the most significant influence on the hydrodynamic performance of the platform. Liu Yuandan et al. [10] conducted hydrodynamic analysis on the tanker to consider the effect of the spacing between the two vessels on hydrodynamics.

Using the potential flow theory to calculate the hydrodynamic performance of semi-submersible platforms has done a lot of work at home and abroad, but based on the three-dimensional potential flow theory, it is rare to analyze the multi-body wave drift force of the system composed of the supply ship and the semi-submersible platform. This paper mainly considers the influence of different external environmental conditions on the average wave drift force of the semi-submersible platform and the effect of the floating body spacing on the average wave drift force of the semi-submersible platform in the presence of external hydrodynamic interference, and then draws some in conclusion. 


\section{Potential Flow Theory}

The force of the fluid on the platform is divided into three parts: wave force, radiation force, and hydrostatic recovery force. The wave force is caused by the incident potential and the diffraction potential, and the calculation formula is as follows:

$$
F_{W}^{1}=F_{W}^{W}+F_{W}^{D}
$$

In

$$
\begin{aligned}
F_{W}^{W} & =i \rho \omega \iint_{S_{0}} \phi_{W} n_{i} \mathrm{~d} s \\
F_{W}^{D} & =i \rho \omega \iint_{S_{0}} \phi_{D} n_{i} \mathrm{~d} s
\end{aligned}
$$

$F_{W}^{1}$ is the first-order wave force. The second-order wave load $F_{W}^{2}$ is one of the important factors for the low-frequency motion of the mooring floating body. $F_{W}^{W}$ is the incident potential and $F_{W}^{D}$ is the diffraction potentiall, the reason is caused by the interaction of two different regular wave components in the irregular wave. The quadratic transfer function (QTF) can be used. To express and estimate. The methods for finding QTF mainly include Newman approximation and full QTF matrix method. In the case of nonlinear strong shallow water conditions, the QTF effect on the off-diagonal line generated by the second-order potential is significant, so in the case of shallow water, the full QTF solution method is used to calculate the wave second-order force.

For $\mathrm{N}$ wave units, the general calculation formula for low frequency wave loads is:

$$
\begin{aligned}
F_{i}^{-}(t)= & \sum_{i}^{N} \sum_{j}^{N}\left\{P_{i j}^{-} \cos \left[-\left(\omega_{i}-\omega_{j}\right) t+\left(\varepsilon_{i}-\varepsilon_{j}\right)\right]\right\} \\
& +\sum_{i}^{N} \sum_{j}^{N}\left\{Q_{i j}^{-} \sin \left[-\left(\omega_{i}-\omega_{j}\right) t+\left(\varepsilon_{i}-\varepsilon_{j}\right)\right]\right\}
\end{aligned}
$$

where $F_{i}^{-}(t)$ is Second-order wave force; $P_{i j}^{-}, Q_{i j}^{-}$represent the second-order difference frequency force in-phase and out-of-phase QTF, respectively; $\omega_{i}$, $\omega_{j}$ represent the frequencies of a pair of wave pairs; $\varepsilon_{i}, \varepsilon_{i j}$ represent the random phases corresponding to the pair of waves.

The expression for $P_{i j}^{-}$in the full QTF calculation is:

$$
\begin{gathered}
P_{i j}^{-}=A_{1}+A_{2}+A_{3}+A_{4}+A_{5} \\
A_{1}=-\oint_{W L} \frac{1}{4} \rho g \xi_{i} \xi_{j} \cos \left(\varepsilon_{i}+\varepsilon_{j}\right) \frac{\bar{N}}{\sqrt{n_{1}^{2}+n_{2}^{2}}} \mathrm{~d} l \\
A_{2}=\iint_{S_{0}} \frac{1}{4} \rho\left|\nabla \phi_{i}\right| \cdot\left|\nabla \phi_{i}\right| \bar{N} \mathrm{~d} s \\
A_{3}=\iint_{S_{0}} \frac{1}{2} \rho\left(X_{i} \cdot \nabla \frac{\partial \Phi j}{\partial t}\right) \bar{N} \mathrm{~d} s \\
A_{4}=\frac{1}{2} M_{S} R_{i} \cdot \ddot{X}_{g j}
\end{gathered}
$$




$$
A_{5}=\iint_{S_{0}} \rho \frac{\partial \Phi^{2}}{\partial t} \bar{N} \mathrm{~d} s
$$

where $W L$ is the waterline position, which is the draught height; $S_{0}$ is the wet surface of the floating body; $X$ is the movement of the floating body; $M_{S}$ is the floating body mass; $R$ is the floating body rotation matrix; $\ddot{X}_{g j}$ is the floating body weight acceleration; $A_{1}$ is the water line integral term; $A_{2}$ is the Bernoulli equation term; $A_{3}$ is the acceleration term; $A_{4}$ is the energy term; $A_{5}$ is the second-order velocity potential.

\section{Calculation Model}

The semi-submersible platform used in this paper is the most common structural form, consisting of an upper deck, four uprights, and two floating bodies. The multi-module system is made up of two semi-submersible platforms connected by connectors. In order to study the influence of the column floating body on the wave drift force of the multi-module system, it is chosen to add four attached structures beside the column. The cross-sectional shape of the attached structure adopts a semicircle, a triangle, and a trapezoid. The platform module is 30 meters long and 20 meters wide. The hydrodynamic model of a semi-submersible platform connected by two modules is shown in Figure 1 .

The basic geometric parameters of the semi-submersible platform model are listed in Table 1. The resupply ship uses the common MVP ship as the research object.
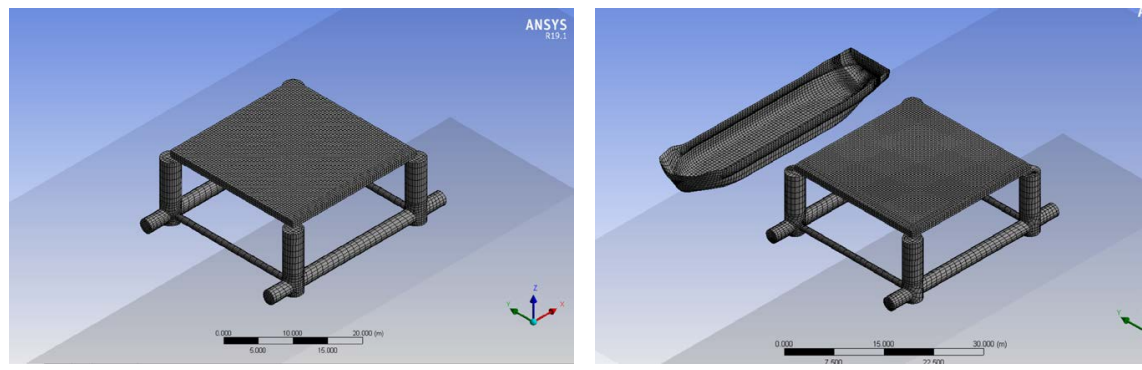

Figure 1. Semi-submersible platform calculation model.

Table 1. Semi-submersible platform parameters.

\begin{tabular}{cc}
\hline Buoy length & $35.0 \mathrm{~m}$ \\
Buoy diameter & $2.3 \mathrm{~m}$ \\
Total length & $35.0 \mathrm{~m}$ \\
Type width & $29.0 \mathrm{~m}$ \\
Main deck length & $25.0 \times 25.0 \mathrm{~m}$ \\
Column spacing & $25.0 \times 25.0 \mathrm{~m}$ \\
Column diameter & $3.2 \mathrm{~m}$ \\
Column height & $11.0 \mathrm{~m}$ \\
Design draught & $4.0 \mathrm{~m}$ \\
\hline
\end{tabular}




\section{Results and Discussion}

\subsection{Influence of Hydrodynamic Interaction on the Steady Drift Force of the Platform}

As you can see from Figure 2.

1) The existence of the replenishment ship has a great influence on the average drift force of the semi-submersible platform. According to the wave action in the direction of 45 degrees, the general trend of the average wave drift force of the three degrees of freedom of the semi-submersible platform is the same. Because of the hydrodynamic interaction between the transport vessel and the semi-submersible platform, the average wave drift force of the curve with the interference of the transport vessel increases.

2) As for the average wave drift force curve of semi-submersible platform rotating in the coordinate plane, it can be seen from the graph that the curve of the disturbance caused by the hydrodynamic action of the transport vessel varies greatly. The rolling is affected by the transport vessel in the whole calculation

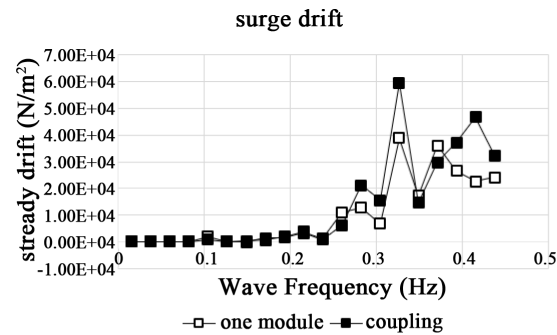

(a)

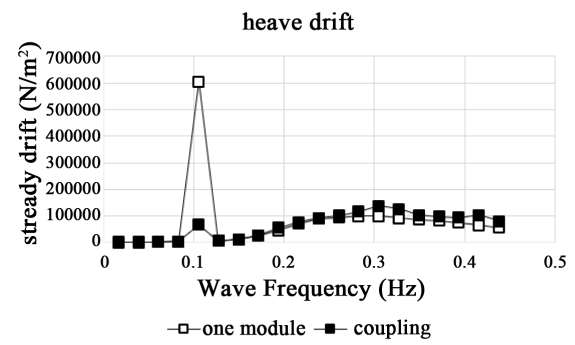

(c)

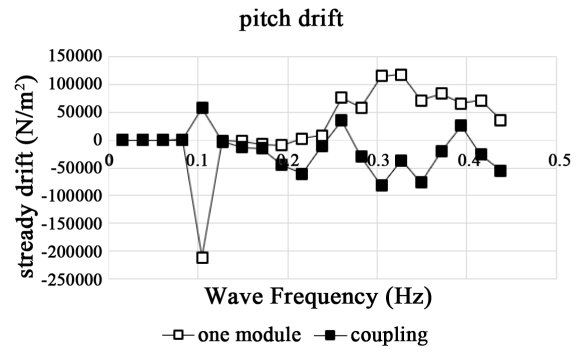

(e)

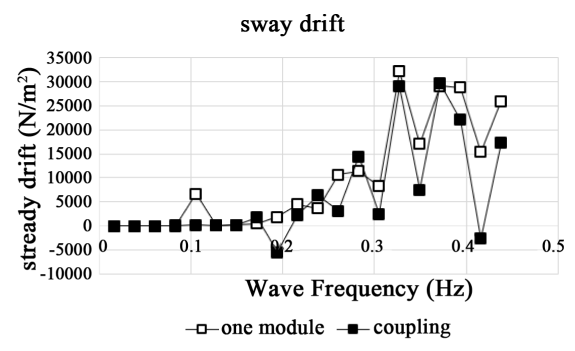

(b)

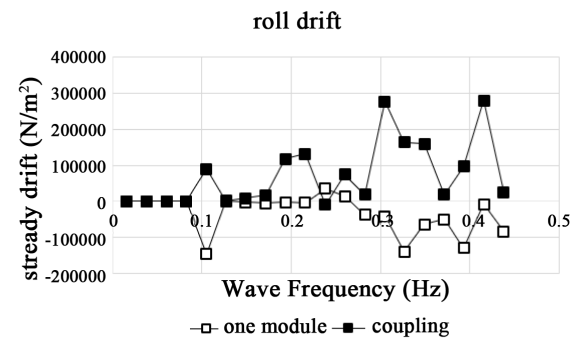

(d)

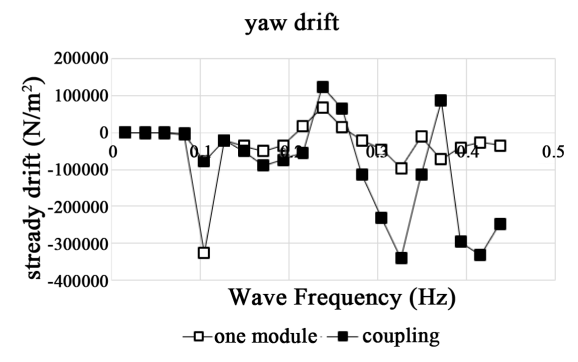

(f)

Figure 2. Comparison of wave mean drift force curves between single module and two modules. (a) sway average wave drift force; (b) sway average wave drift force; (c) heave average wave drift force; (d) roll average wave drift force; (e) pitch average wave drift force; (f) Average wave drift force of yaw. 
frequency. The average wave drift force increases about three times, and the pitch curve changes from the original positive curve to the negative curve. The change of yaw is not as obvious as the first two, but the value of yaw increases sharply in the high frequency part.

\subsection{The Influence of the Distance between Two Floating Bodies on the Drift Force}

Ship berthing distance is one of the important factors affecting the average drift force between two floating objects. The average wave drift forces of six degrees of freedom for semi-submersible platforms with different spacing are considered as shown in Figure 3. The two-module model analyses the 45-degree direction of $\mathrm{X}$-axis symmetrical incidence angle. For the average drift force of surge and pitch waves, the change of distance has little effect on the average drift force of semi-submersible platform, and there is no regular change at individual peaks. The main reason is that the arrangement of the replenishment ship along the $\mathrm{X}$-axis has little influence on the average drift force of pitch and pitch. Swaying

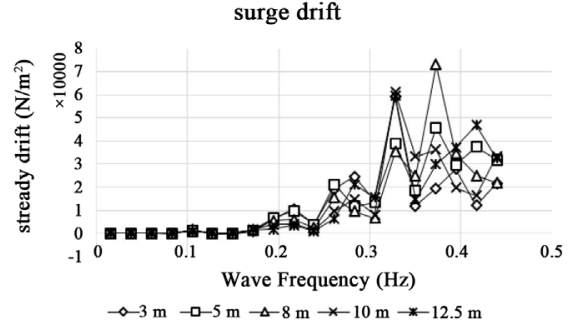

(a)

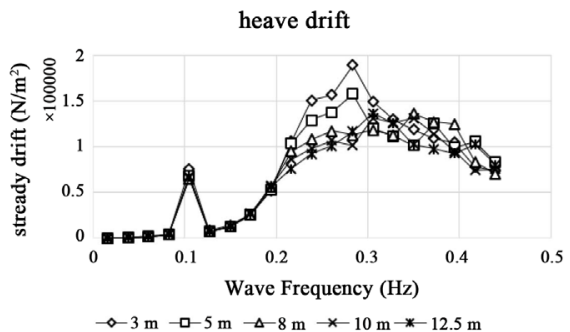

(c)

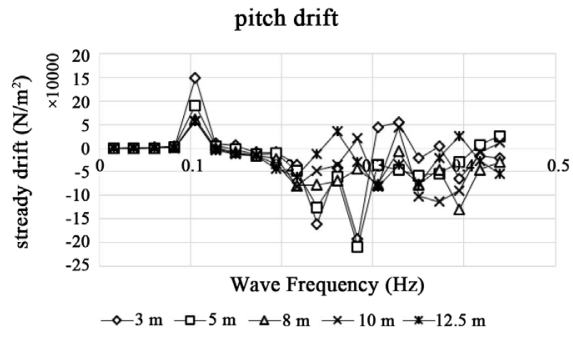

(e)

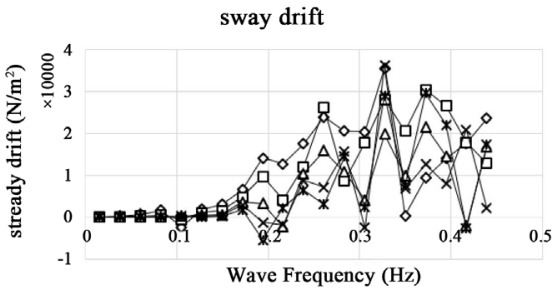

$-0-3 \mathrm{~m}-\mathrm{q}-5 \mathrm{~m}-\Delta-8 \mathrm{~m}-10 \mathrm{~m} \rightarrow-12.5 \mathrm{~m}$

(b)

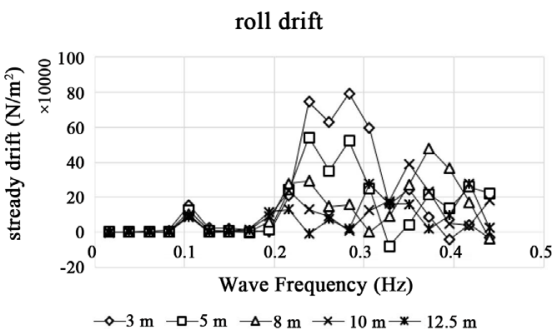

(d)

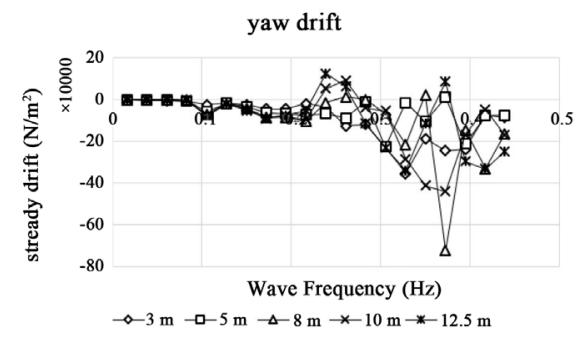

(f)

Figure 3. Average drift force of semi-submersible platform with different spacing. (a) sway average wave drift force; (b) sway average wave drift force; (c) heave average wave drift force; (d) roll average wave drift force; (e) pitch average wave drift force; (f) average wave drift force of yaw. 
and rolling are sensitive to the change of spacing. The graph also shows that the average drift force of swaying and rolling waves decreases with the increase of spacing. The average drift force of some semi-submersible platforms with wave frequency greater than $0.2 \mathrm{~Hz}$ also shows that the larger the distance, the smaller the value.

Because the greater the spacing between the two floats, the hydrodynamic interference is weaker. Therefore, as the pitch increases, the average drift force of the semi-submersible platform is less and less affected, and the value on the curve is lower and lower. The average drift force of the yaw wave fluctuates in the part of the wave frequency greater than $0.3 \mathrm{~Hz}$. The overall trend shows that the change of the distance between the two floating objects will affect the drift force of the semi-submersible platform to some extent. This effect may increase the burden on the platform mooring system.

\section{Conclusion}

The hydrodynamic interference of the replenishment ship to the semi-submersible platform in the same flow field is more obvious in the middle and high frequency part, and the shielding effect of the replenishment ship to the semi-submersible platform is not obvious under the action of inclined waves, but the existence of the replenishment ship still interferes with the average drift force of the semi-submersible platform. From the effect of different spacing on the average drift force, the effect of spacing on the wave drift force of semi-submersible platform is non-linear, but the larger the spacing, the smaller the effect of the replenishment ship on the semi-submersible platform. The effect of wave incidence angle on the average drift force of semi-submersible platform is mainly reflected in the middle and high frequencies. Within this frequency range, the semi-submersible platform will produce larger mooring force, which is not conducive to positioning. In the low frequency part, the wave drift force of semi-submersible platform is small and insensitive to the change of wave direction and angle.

\section{Conflicts of Interest}

The authors declare no conflicts of interest regarding the publication of this paper.

\section{References}

[1] Tong, B., Yang, J. and Li, X. (2008) Coupling Dynamic Analysis of Catenary Mooring System in Deepwater Semi-Submersible Platform. China Platform, 23, 17.

[2] Ohkusu, M. (1974) Ship Motions in Vicinity of a Structure. Behavior of Offshore Structure, Trondheim, Vol. 1, 284-306.

[3] Ogilvie, T.F. (1983) Second Order Hydrodynamic Effects on Ocean Platforms. International Workshop on Ship and Platform Motions, Berkeley, 205-265.

[4] Islam, M.R. (2000) Numerical Investigation of Slowly Varying Drift Forces of Multiple Floating Bodies in Short Crested Irregular Waves. The International Society of 
Offshore \& Polar Engineering, Mountain View.

[5] Hong, J.H., Kim, S.K., Cho, Y.R., et al. (2004) Numerical and Experimental Study on Hydrodynamic Interaction of Side-by-Side Moored Multiple Vessels. Ocean Engineering, 32, 783-801. https://doi.org/10.1016/j.oceaneng.2004.10.003

[6] Pessoa, J., Nuno Fonseca, C. and Soares, G. (2015) Numerical Study of the Coupled Motion Responses in Waves of Side-by-Side LNG Floating Systems. Applied Ocean Research, 51, 350-366. https://doi.org/10.1016/j.apor.2015.01.012

[7] Wang, K., He, D., Shi, P., et al. (2014) Analysis of Wave Drift Force of Semi-Submersible Oil Production Platform. Journal of Ship Mechanics, 18, 406-412.

[8] Liu, Z. and Chen, C. (2018) Response Analysis of Hydrodynamic Force and Mooring System of Semi-Submersible Platform under Wind, Wave and Current. Ship \& Ocean Engineering, 47, 75-79.

[9] Zhou, W., Hu, Z. and Zhao, D. (2018) Hydrodynamic Interference Analysis of Different Waves Going down to LNGC by FLNG Operation. Journal of Harbin Institute of Technology, 50, 114-123.

[10] Liu, Y., Xiong, Z., Liu, J., et al. (2012) Research on Hydrodynamic Interaction of Tanker Based on AQWA. Ship Science and Technology, 34, 13-15+17+22. 